\title{
Collective Responses to Covid-19 and Climate Change
}

\author{
ANDREA S. ASKER \\ Stockholm University and Institute for Futures Studies \\ H. ORRI STEFÁNSSON \\ Stockholm University and Swedish Collegium for Advanced Study
}

\begin{abstract}
Both individuals and governments around the world have willingly sacrificed a great deal to meet the collective action problem posed by Covid-19. This has provided some commentators with newfound hope about the possibility that we will be able to solve what is arguably the greatest collective action problem of all time: global climate change. In this paper we argue that this is overly optimistic. We defend two main claims. First, these two collective action problems are so different that the actions that individuals have taken to try to solve the problem posed by Covid-19 unfortunately provide little indication that we will be able to solve the problem posed by climate change. Second, the actions that states have taken in response to Covid-19 might-if anything-even be evidence that they will continue to fail to cooperate towards a solution to the climate crisis.
\end{abstract}

Keywords: climate change, collective action, Covid-19, decision-making, harm

JEL Classification: D700, I120, I180

\section{INTRODUCTION}

The collective response to the Covid-19 pandemic is historically unprecedented (Ljungqvist 2020). In most countries, the public has supported, or at least accepted, measures that have restricted their freedoms and liberties in ways that have no counterpart in modern history. For the greater part of 2020, the majority of people in most European countries supported national lockdowns and restrictions (European Parliament Public Opinion Monitoring Unit 2020). Similarly, governments around the world have imposed measures that, predictably, have led to the

Authors' Note: We are grateful to Krister Bykvist, Joe Roussos, the special issue editors of EJPE, and three anonymous referees for very helpful comments and suggestions that helped us improve the paper. 
greatest economic recession in almost a century. For instance, the unemployment rate soared in both the United States and the European Union, and in many countries it rose even faster than it had done during the Great Depression of the 1930s (Krogstad and Noe-Bustamante 2021).

The fact that both individuals and governments have willingly sacrificed such great interests to meet the collective problem of the Covid-19 pandemic has provided some commentators with newfound hope about the possibility that we will be able to solve what is arguably the greatest collective action problem of all time: global climate change. For instance, The Guardian's columnist Owen Jones wrote in the spring of 2020 that global responses to Covid-19 show that strong and urgent actions like those needed in response to the climate crisis "can be done" (Jones 2020). Similarly, Australia's former chief scientist, Professor Ian Chubb, wrote in the summer of 2020 that the pandemic has taught us "that communities of individuals will act cohesively when the stakes are high", which proved that threats like the climate crisis could similarly be responded to (Chubb 2020).

Unfortunately, we think that these commentators are overly optimistic. Our examination of the collective action problems that Covid-19 and the climate crisis constitute lead us to two conclusions. First, these two collective action problems are so different that the actions that individuals have taken to try to solve one (Covid-19) unfortunately provide little indication that we will be able to solve the other (climate change). Second, the actions that states have taken in response to Covid-19 might-if anything-serve as evidence that they will continue to fail to cooperate towards a solution to the climate crisis. Our main aim in this paper is to illustrate that it is far from clear that the observed responses to Covid-19 should make us optimistic about the chances of appropriate responses to the climate crisis. ${ }^{1}$

\section{INDIVIDUAL AGENTS}

In much of the philosophical discussion of collective action problems there is a tendency to apply the same template to all such problems and treat them as structurally analogous. In doing so, however, there is a risk of missing important differences. We suggest that the inference

\footnotetext{
1 Schliesser and Winsberg (2020) point out other important differences between climate change and Covid-19 (in particular, early in the pandemic), for instance, that the scientific understanding and cross-disciplinary discussion of climate change is much greater and more sophisticated than the understandig and discussion of Covid19.
} 
from the collective response by individuals to the pandemic to their anticipated response to the climate crisis is a case in point. Because the decision problem that individuals face differs in important respects between these two collective action problems, we should be careful in making inferences from one to the other. (By 'collective action problem', we here simply mean a decision problem where a group of at least two agents act individually, but, for each individual, the outcome that they get depends at least partly on the actions of others in the collective. An 'agent' can, for our purposes, be anything from a single person to a whole nation.)

The collective action problem posed by the pandemic is similar to that of climate change in that there is some morally significant outcome caused by many individuals acting in a certain way, but no individual action fully determines the outcome. In particular, both the pandemic and the climate crisis will be very harmful regardless of the actions of any one individual. Nevertheless, the decision problems faced by individuals differ between these two collective action problems, both in terms of the type of uncertainty people face, and in terms of how individual actions stand in relation to the harm produced by these two problems.

Consider first an individual (private) decision maker in the pandemic situation. To keep things simple we shall assume that, when it comes to Covid-19 decision problems, the individuals we consider have the same and rather simple preferences. In particular, we assume that they prefer the pandemic to end sooner rather than later and that they prefer its health and fatality effects to be less rather than more severe. In addition, we assume that individuals prefer that neither themselves nor their family and friends get infected by the coronavirus.

We shall moreover assume that these are the only preferences that are relevant to the decision problem we describe below. This is not to deny that individuals may have other interests related to the pandemic. For instance, they may prefer the economic effects of the pandemic to be less rather than more severe. Similarly, they may prefer that the measures to contain the pandemic limit their freedom as little as possible. ${ }^{2}$ But we assume that they do not take these interests to be relevant

\footnotetext{
${ }^{2}$ Of course, limits on freedom and economic suppression may be a function of the severity of the pandemic, which in turn is largely determined by individuals collectively spreading the virus. But this is not the harm that we take individuals to be primarily concerned with when making decisions in this context, although it may of course be part of their total concern.
} 
when making a decision in examples like that below. So, when an individual reasons about such a decision, the relevant outcomes concern primarily how many (if any) new infections and fatalities the decision may cause, and, perhaps, who might become infected as a result of the decision.

Now consider Jane, who has the above preferences, but wants to meet her friends and family in a neighbouring town. The only means she has of reaching the town is taking public transport. Let us assume that Jane can do so without breaking any law (as was true in most countries even at the height of the pandemic), although it goes against official recommendations.

What does Jane's decision problem look like? To keep things simple, let us ignore any (for example, social) sanctions of violating Covid-19 recommendations. It would seem, then, that the main uncertainties that Jane has to consider concern, on the one hand, whether she is already infected, and, on the other hand, whether she would become infected if she were to take the trip. Moreover, given that most countries published and regularly updated information about the rate of infection in different areas and, in addition made testing widely available (at least during later waves), it would be plausible to assume that Jane can ascribe some meaningful probabilities to these uncertainties; that is, she has a meaningful way of assessing both the probability that she is already infected and the probability that she will get infected if she takes the trip. (In addition, the widely published $R$ number may give Jane an indication of how many she should expect to infect if she is or becomes infected.) This is one feature that makes individuals' Covid-19 decisions importantly different from individuals' climate decisions, as we shall shortly explain. Table 1 summarises Jane's decision problem.

Jane's preferences are as follows: if she is infected, then she prefers to stay home. If she would get infected, were she to take the trip, then she also prefers to stay home. However, if she is not infected, nor would get infected were she to take the trip, then she prefers to take the trip.

Since each new infection can be considered a significant harm (to the infected person), and since someone who is infected has a considerable chance of infecting at least one other person, an individual in Jane's position has a considerable chance of making a significant difference in harm. This is another feature that makes individuals' Covid-19 decisions importantly different from individual climate decisions, to which we turn next. 


\begin{tabular}{c||lll} 
& Already infected & Gets infected if trip is taken & \multicolumn{1}{c}{ No infection } \\
\hline \hline \multirow{3}{*}{ Take trip } & $\begin{array}{l}\text { Risks infecting } \\
\text { others, but meets } \\
\text { family and friends }\end{array}$ & $\begin{array}{l}\text { Risks illness and infecting } \\
\text { others, but meets family } \\
\text { and friends }\end{array}$ & $\begin{array}{l}\text { Gets to meet family } \\
\text { and friends, without } \\
\text { infecting or falling ill }\end{array}$ \\
Stay home & $\begin{array}{l}\text { Misses family and } \\
\text { friends }\end{array}$ & Misses family and friends & $\begin{array}{l}\text { Misses family and } \\
\text { friends }\end{array}$
\end{tabular}

Table 1: Jane's decision problem.

Consider an agent-call him Walt-who is concerned by the harm of climate change, but nevertheless enjoys going on Sunday drives in his gas-guzzling SUV. (We assume that most readers will recognise Walt's predicament, at least if they substitute Sunday drives for their favourite greenhouse gas emitting activity, such as flying, buying new jeans, eating meat, and so on). Opinions differ as to whether Walt's Sunday drive, and even his lifetime consumption and transportation choices, has any chance of affecting the harm of climate change. ${ }^{3}$ But for the analogy between climate and Covid-19 decisions to stand any chance-that is, to give some chance to the hypothesis we want to refute-let us assume that Walt's drive has some chance of making some difference to the climate problem.

There is a broad consensus in the climate ethics literature that the problem facing Walt is either a triggering case or an imperceptible harm case, or potentially both. ${ }^{4}$ On the one hand, there is a possibility that the emission from his drive moves the concentration of greenhouse gas (or the corresponding temperature) closer to a threshold, which is such that if passed, it will trigger some harmful event, such as a storm, flood, or drought. ${ }^{5}$ On the other hand, it is possible that the greenhouse gas emission from his drive warms the climate by a tiny degree, which makes living conditions in some part of the world imperceptibly worse. So, either Walt's actions will greatly increase harm by, say, increasing

\footnotetext{
${ }^{3}$ For example, Kingston and Sinnott-Armstrong (2018) argue that an individual action makes no difference with respect to climate change, whereas Morgan-Knapp and Goodman (2015) and Broome (2019) argue that it can make a difference.

${ }^{4}$ See for example Parfit (1986), Kagan (2011), Nefsky (2011), Morgan-Knapp and Goodman (2015), Cullity (2019), and Broome (2019) for detailed discussions of thresholds and imperceptible harms.

${ }^{5}$ This simplified explanation might make it seem as if greenhouse gas concentrations build up linearly over time whereupon some individual action hits a threshold that triggers a harm, but this is not the only threshold view. Some recent accounts, such as Broome (2019), suggest instead that because of the atmosphere's instability, a small disturbance may trigger significant climate harms without assuming that there are fixed thresholds.
} 
the number of harmful climate events-which is (at least subjectively) unlikely-or it will cause imperceptible harm, or possibly both.

Now, it is widely accepted that climate change related decisions are associated with severe, maybe even extreme, uncertainty (Bradley and Steele 2015). In particular, there is no meaningful way in which Walt can estimate the probability that his action will make a perceptible difference when it comes to climate related harms. For instance, he cannot in any meaningful and precise way compare the probability that some harmful climate event (drought, storm, flood, and so on) will occur if he goes for a drive with the probability that such an event will not occur if he goes for the drive. At best, he may have good reason to believe that the drive is more likely to cause such an event than to prevent it; but it would be very implausible to claim that Walt has any meaningful way of assessing how much these probabilities differ. And the same holds for other potential climate related harms from his Sunday drive. So, in this sense, his uncertainty is more severe than (and qualitatively different from) Jane's.

We are now in a position to see that Walt's decision problem is in important ways different from Jane's. First, as explained above, there is a difference in how severe their uncertainties are. Second, there are differences in how individual actions stand in relation to the respective outcomes. For instance, there is no chance that Jane's decision makes the Covid-19 problem imperceptibly worse. If she makes the problem worse, then that is by getting herself infected, and/or infecting others, which is not imperceptible. ${ }^{6}$ Now, by getting herself infected, and/or infecting others, she might move society a tiny (perhaps imperceptible) bit closer to a threshold the passing of which triggers a lockdown or some other severe restriction. So, a part of the harm that her action could cause shares this feature with the harm that Walt's climate decision could cause. However, our point is that if Jane's actions cause (Covid-19 related) harm, then there is no chance that the overall (Covid-19 related) harm is imperceptible, since one more person getting infected is not imperceptible. And that is an important difference between her decision problem and Walt's. In addition, as we have seen, there is, in the midst of the pandemic, a significant chance that Jane causes a significant harm

\footnotetext{
${ }^{6}$ What about asymptomatic infections? If Jane infects a person who has no symptoms, and that person does not infect anyone else (or only causes an asymptomatic infection, and so on) then her action causes no harm, not an imperceptible harm. Unless, that is, the asymptomatic infection physically harms the person despite the lack of symptoms, in which case it would plausibly count as a perceptible harm.
} 
by infecting one or more people, which could even result in them dying. In contrast, Walt will either cause a great increase in harm (which is unlikely) and/or cause an imperceptible harm.

There is an additional difference in terms of how individuals might reason about their respective decision problems. Jane might reason as follows:

If I take the trip, and one of the unfortunate outcomes occurs, then there is at least one ex post identifiable person whom I harm in the very near future. Moreover, if I cause someone to be infected, then that infection could potentially be traced back to me. I would not be able to live with that.

In contrast, Walt might reason as follows:

If I go for the drive, there are many people who are exposed to a tiny risk of harm. Even ex post, however, no actual harm can be traced back to me. ${ }^{7}$ In addition, these harms-if they materialise-are likely to occur far into the future, perhaps even after my death.

Now, one could of course doubt that these last differences between the two decision problems are morally relevant. That a harm cannot be traced back to my action would seem irrelevant to its moral standing. Similarly, whether a harm is immediate should not matter (much) morally. Nevertheless, these differences are relevant to how much we can infer about people's behaviour from one problem to the other. The same is true of the differences between these decision problems when it comes to the level of uncertainty and the relationship between actions and outcomes. These differences undermine the plausibility of inferring, from the fact that a large part of the global population has shown restraint in situations analogous to Jane's, that a large part of the global population can be convinced to show restraint in situations analogous to Walt's. In other words, that many people seem to have sacrificed their short-term interest for the 'public good' in the Covid-19 pandemic is not, by itself, strong evidence that people will sacrifice their short-term interest in response to the climate crisis.

\footnotetext{
${ }^{7}$ For instance, Sinnott-Armstrong (2005, 299; emphasis added) says: "No storms or floods, or droughts or heat waves can be traced to my individual act of driving".
} 


\section{STATE AGENTS}

Let us turn now to the collective action problem faced by states in the Covid-19 pandemic. As previously discussed, most states intentionally sacrificed an unprecedented proportion of their economy at least during parts of 2020 in order to fight the pandemic. In other words, states by and large prioritised containing the pandemic over avoiding negative short-term economic effects. ${ }^{8}$ It is not hard to understand why this has given some hope that states will take the necessary actions to limit the harm of the climate crisis. These actions will be costly in the short run, ${ }^{9}$ which is a reason why states have been reluctant to take them. But since states have shown willingness to accept such short-term costs in response to the pandemic, it might seem reasonable to believe that states will accept such costs in response to the climate crisis. ${ }^{10}$

Unfortunately, an examination of the decision problem that states have faced and the actions that they have taken suggests that this newfound hope may be too optimistic, as we argue in this section. However, as in the previous section, our aim is not to conclusively show that the actions that have been taken do not bode well for the climate. Instead, our aim is to explain why there is reason to be sceptical of claims (such as those we cited in our introduction) that states' actions in the face of Covid-19 do bode well for the climate.

To explain this, we need to make some empirical assumptions. But our analysis is not sensitive to any precise empirical assumptions; quantitively close assumptions would lead to the same qualitative conclu-

\footnotetext{
${ }^{8}$ Of course, containing the pandemic also involves avoiding some negative economic effects, for example, by preventing productivity loss from sick leave. In addition, an aggressive early reaction to the pandemic may be good for economic growth in the medium-term, as witnessed by China's performance. After having shrunk by $6.8 \%$ in the first quarter of 2020, China's GDP grew by $6.5 \%$ in the fourth quarter of the year (both in comparison with the same quarters the year before); and overall, China's GDP grew by $2.8 \%$ in 2020, making it the only 'major world economy' to grow in 2020 (Cheng 2021). However, for our purposes, the important point is that many states took a gamble, whereby they sacrificed an unprecedent proportion of their economy in the short-term.

${ }^{9}$ It is worth noting, however, that the current generations could, in theory, take these actions at no cost to themselves, by 'borrowing' from future generations, as Broome (2012) has pointed out.

${ }^{10}$ What counts as 'short-term' versus 'long-term' is of course very different in the Covid-19 problem compared to the climate problem: the 'long-term' as far as Covid-19 is concerned is part of the 'short-term' as far as the climate crisis is concerned. This point of course only further supports our claim, namely, that strong action against Covid-19 might not provide much evidence that there will be strong action against the climate crisis. Since our aim is to focus on other arguments for our claim, we set aside this disanalogy between the two problems.
} 
sion. Still, one could simply read what follows as claims conditional on the assumptions we make.

The first empirical assumption concerns the so-called infectionfatality ratio from Covid-19, which is the ratio (typically presented as a percentage) between the number of people who die from Covid-19 and the estimated number of people who have been infected by the coronavirus. As has been much discussed, the infection-fatality ratio is considerably lower than the rate reported in most countries, which is based on officially confirmed cases and is called the case-fatality ratio. A large number of Covid-19 cases are not officially confirmed, and mild cases are, of course, heavily overrepresented amongst these. And unsurprisingly, those countries that did the most testing reported the lowest casefatality ratio (Ljungqvist 2020).

In Iceland, which is one of few countries that from the start of the pandemic tested even people without symptoms, the case-fatality ratio in July 2021 is $0.52 \%$ (The Directorate of Health 2021). Countries with less developed health-care systems than Iceland's might have a higher infection-fatality ratio. But countries that have a lower proportion of very old people may have an even lower infection-fatality ratio (Lawal 2021). Thus, the average global infection-fatality ratio might not be far from the case-fatality ratio reported in Iceland, which we use below.

A second empirical assumption we need to make concerns how many people would have to be infected to achieve natural herd immunity, that is, herd immunity through natural infection as opposed to vaccination. The estimates vary, and differ for different countries, but the estimated figures for rich countries like Sweden, The Netherlands, and the United States are around $70 \%$, but lower for most poorer countries (Kwok et al. 2020). Putting these two figures together, one could estimate that a reasonable upper bound (using the $70 \%$ figure) on the total number of fatalities from a world-wide natural herd immunity would be almost 29 million.

The social and economic impact of the measures taken to contain the pandemic have been much discussed. Global GDP is estimated to have fallen by $4.3 \%$ in 2020 (the highest annual drop since the Great Depression) (The Economist 2021), while unemployment rates soared. However, the impact on vulnerable people in developing countries has been even more severe. For instance, David Beasley, Executive Director of the United Nation's World Food Programme, warned in December 2020 that the number of people at risk of starvation had doubled, from 
135 million to 270 million, due to the global recession caused mainly by states' response to the pandemic (The World Bank 2020; United Nations 2020).

It is instructive to try to compare the expected number of life years lost from such an extreme increase in the number of people risking starvation with the expected number of life years lost from world-wide natural herd immunity to the coronavirus. For that is one way of determining whether the cost of halting economic activity in order to contain the virus was worth paying. Such a comparison of course ignores the early deaths that we should expect as a result of increased unemployment in richer countries (Laditka and Laditka 2016), but it at least gives some indication of the cost, in terms of life years lost, of halting economic activity to contain the pandemic. ${ }^{11}$

A recent study has found that the average number of life years lost in a Covid-19 death in the United States is 9.34 (Quast et al. 2020). Assuming that the number would be the same in a global population with natural herd immunity, one could expect that the total number of life years lost through world-wide natural herd immunity would be almost 269 million. However, the average number of life years lost when someone starves is much higher. In fact, currently around half of those living in extreme poverty are under the age of 18 . If, say, $10 \%$ of these 135 million additional people that risk starvation actually starve, and if, say, the average number of life years lost when someone starves to death is 40 , then that adds up to 540 million life years lost. And note that this only includes the additional people that risked starvation as a result of the recession in 2020. As the recession continues, more people will surely risk starvation and experience other harms, such as poverty and missed education, which will eventually translate into additional life years lost.

In light of the above, it could well be that if all states had decided, at the start of the pandemic, to protect the very old and vulnerable while allowing "those who are at minimal risk of death to live their lives normally to build up immunity to the virus through natural infection", as urged by the Great Barrington Declaration (Kulldorf, Gupta, and

\footnotetext{
${ }^{11}$ In addition, focusing only on lost life years ignores important losses in quality of life that could be captured by a quality-adjusted life year (QALY) analysis. We suspect that a QALY analysis would only further strengthen the argument for our claim that it is far from evident that states have together brought about an optimal solution to Covid-19. After all, strict measures such as the closing of restaurants, curfews, and preventing people from gathering has negative effects on the quality of people's lives that may not be fully translated into lost life years. However, as we do not have the data for such a rich QALY analysis, we will focus on life years lost.
} 
Bhattacharya 2020), then the world as a whole would have achieved an outcome that is better, in terms of the total number of life years lost, than the outcome that we are heading towards. Now, we should stress that the above is highly speculative and very far from conclusive. Moreover, the Great Barrington Declaration has a number of prominent critics, such as the head of the World Health Organization (The Guardian 2020). But, for now, we simply want to suggest there may be reasons to doubt that the strong actions that states have taken in response to Covid-19 are globally optimal, as for instance judged by life years lost.

Now, the global recession, which by the end of 2020 had resulted in the number of people risking starvation doubling, was not caused by the coronavirus as such, but rather the global response to the virus, such as the intentional halting of economic activity. Hence, a plausible counterfactual assumption, that we will make below, is that the global economic recession would have been considerably lessened (if not avoided) if states had decided, at the start of the pandemic, to protect the very old and vulnerable while allowing others to build up natural immunity.

However, no state could have single-handedly avoided the global recession, and thus, given their reliance on the global economy, no state could have avoided a national recession. In addition, it may have beenor at least perceived to have been-in the national (short-term) interest of each state to impose strict restrictions. In particular, there was a widespread belief amongst policy-makers that lockdowns and other strict measures would reduce the number of local fatalities, even without some sort of global cooperation in the fight against the pandemicas revealed by decisions to almost close borders while failing to properly cooperate on, for example, global vaccine programs. ${ }^{12}$

Now, such 'vaccine nationalism' (Eaton 2021) and increased (unilateral) border controls might in itself be taken as evidence that increased global cooperation in the fight against climate change is unlikely. In what follows we, however, want to make a somewhat different argument against the hypothesis that states' actions in the pandemic are evidence that they will succeed in cooperating on a response to climate change; an argument that is based on examining more closely the collective action problem in which states have found themselves.

To make this argument we rely on two additional assumptions about the attitudes of the state agents with which we are concerned. First, we assume that each state has two goals that are relevant to the decision

${ }^{12}$ See, for example, Eaton (2021). 


\begin{tabular}{|c|c|c|}
\hline & Others aim for herd immunity & Others impose strict restrictions \\
\hline $\begin{array}{l}\text { Aim for herd } \\
\text { immunity }\end{array}$ & $\begin{array}{l}\text { Global recession avoided } \\
\text { No local recession } \\
\text { More (short-term) local fatalities }\end{array}$ & $\begin{array}{l}\text { Global recession } \\
\text { Mild local recession } \\
\text { More (short-term) local fatalities }\end{array}$ \\
\hline $\begin{array}{l}\text { Impose strict } \\
\text { restrictions }\end{array}$ & $\begin{array}{l}\text { Global recession } \\
\text { Mild local recession } \\
\text { Fewer (short-term) local fatalities }\end{array}$ & $\begin{array}{l}\text { Global recession } \\
\text { Local recession } \\
\text { Fewer (short-term) local fatalities }\end{array}$ \\
\hline
\end{tabular}

Table 2: States' decision problem.

problem at hand. On the one hand, each state would (other things being equal) like fewer rather than more of its citizens to get infected by Covid-19. On the other hand, each state would (other things being equal) like the measures taken to contain the pandemic to have as little negative economic effect as possible.

In light of the above, one could use Table 2 to formulate the decision problem that each state found itself in when deciding between imposing strict restrictions and aiming for natural heard immunity. To simplify, we assume that the states whose decision is not being modelled all act in the same way (that is, either they all opt for strict measures, or they all opt for herd immunity). Another simplification is that we ignore the many degrees that the different variables can take; for instance, we assume that there is either no local recession, or mild local recession, or local recession, and we assume that there are either more or fewer shortterm local fatalities. Finally, by local fatalities, we here mean fatalities directly due to the coronavirus, not including the indirect fatalities from Covid-19 such as those due to poverty and unemployment.

Most states opted for strict restrictions. If the above is the correct framing of the decision problems that states faced, and, given that each state prioritised (in the short-term) fewer local fatalities over increased local economic performance, strict restrictions moreover seem to have been the rational choice. Whatever 'others' do in this problem, each state does better by imposing strict restrictions. Therefore, by each state acting individually rationally, they all impose strict restrictions-which is indeed the outcome we have observed.

However, given what we said above, one might reasonably think that the choice that most states made does not bode well for the prospects of solving the climate crisis. Granted, states have accepted an enormous economic cost to try to deal with the corona crisis, which, as previously mentioned, some have taken as evidence that perhaps they will do so too in response to the climate crisis. But recall that it is far from evi- 
dent, as we have argued, that the outcome where each country imposes strict measures is optimal from a global point of view, for instance, when counting global life years lost. In fact, we suggested that there might have been fewer global life years lost had states all aimed for natural herd immunity. In addition, imposing strict measures seems to have been perceived by states to serve their own (short-term) interests.

The economic costs that states have accepted to try to limit the harm of Covid-19 may, therefore, have resulted in an outcome that is suboptimal for the global collective, even though it may have been optimal for each individual state. In contrasts, the economic costs that states will presumably (in the short run) have to accept to limit the harm from climate change are costs of reaching the outcome that is optimal for the global collective, but suboptimal for each individual state, at least as far as their own short-term interests are concerned (which would be best served by free-riding on the actions of other states). So, contrary to what seems to be a widespread view, it is far from evident that states' actions in response to Covid-19 bring hope for the prospect of responding to the climate crisis.

\section{CONCLUDING REMARKS}

In conclusion, we have argued that, contrary to common claims-both by journalists and scientists-it is at least questionable that individuals' and states' responses to the Covid-19 pandemic should give us much hope about an appropriate response to the impeding climate catastrophe. The Covid-19 decision problem that individuals face is simply too different from the individual climate decision problem for their actions in one problem to provide evidence of how they will act in the other. And it is far from clear that the Covid-19 decisions that most states have made should give us hope that global cooperation to solve the climate crisis will be reached.

\section{REFERENCES}

Bradley, Richard, and Katie Steele. 2015. "Making Climate Decisions.” Philosophy Compass 10 (11): 799-810.

Broome, John. 2012. Climate Matters: Ethics in a Warming World. New York, NY: W. W. Norton \& Company.

Broome, John. 2019. “Against Denialism.” The Monist 102 (1): 110-129.

Cheng, Jonathan. 2021. "China Is the Only Major Economy to Report Economic Growth for 2020.” Wall Street Journal, January 18, 2021. https:/www.wsj.com/articles/ china-is-the-only-major-economy-to-report-economic-growth-for-2020-11610936187. 
Chubb, Ian. 2020. "Australia's Covid-19 Response Shows We Can Confront Major Crises. Threats to Our Planet Should Be Next." The Guardian, July 29, 2020. https://www.theguardian.com/commentisfree/2020/jul/29/australias-covid-19response-shows-we-can-confront-major-crises-threats-to-our-planet-should-be-next.

Cullity, Garrett. 2019. "Climate Harms.” The Monist 102 (1): 22-41.

Eaton, Lynn. 2021. “Covid-19: WHO Warns Against 'Vaccine Nationalism' or Face Further Virus Mutations." BMJ 372 (8278): n296.

European Parliament Public Opinion Monitoring Unit. 2020. "Public Opinion in the Time of Covid-19 (Public Opinion Monitoring at a Glance)." European Parliament Public Opinion Monitoring Unit, December 2020. https://www.europarl. europa.eu/at-your-service/files/be-heard/eurobarometer/2020/covid19/en-publicopinion-in-the-time-of-covid19-202012.pdf.

Jones, Owen. 2020. “Why Don't We Treat the Climate Crisis with the Same Urgency as Coronavirus?" The Guardian, March 5, 2020. https://www.theguardian.com/ commentisfree/2020/mar/05/governments-coronavirus-urgent-climate-crisis.

Kagan, Shelly. 2011. “Do I Make a Difference?” Philosophy \& Public Affairs 39 (2): 105-141. Kingston, Ewan, and Walter Sinnott-Armstrong. 2018. "What's Wrong with Joyguzzling?" Ethical Theory and Moral Practice 21 (1): 169-186.

Krogstad, Jens M., and Luis Noe-Bustamante. 2021. "Most U.S. Citizens Report a Campaign Contacted Them in 2020, but Latinos and Asians Less Likely to Say So." Pew Research Center, January 29, 2021. https://www.pewresearch.org/fact-tank/2021/ 01/29/most-u-s-citizens-report-a-campaign-contacted-them-in-2020-but-latinosand-asians-less-likely-to-say-so/.

Kulldorf, Martin, Sunetra Gupta, and Jay Bhattacharya. 2020. “The Great Barrington Declaration." Accessed February 1, 2021. https://gbdeclaration.org/.

Kwok, Kin On, Florence Lai, Wan In Wei, Samuel Yeung Shan Wong, and Julian W. T. Tang. 2020. "Herd Immunity - Estimating the Level Required to Halt the COVID-19 Epidemics in Affected Countries." Journal of Infection 80 (6): e32-e33.

Laditka, James N., and Sarah B. Laditka. 2016. "Unemployment, Disability and Life Expectancy in the United States: A Life Course Study." Disability and Health Journal 9 (1): 46-53.

Lawal, Yakubu. 2021. “Africa's Low COVID-19 Mortality Rate: A Paradox?” International Journal of Infectious Diseases 102: 118-122.

Ljungqvist, Frederik C. 2020. Corona: Ett Historiskt Perspektiv på Vår Tids Pandemi. Stockholm: Dialogos Förlag.

Morgan-Knapp, Christopher, and Charles Goodman. 2015. "Consequentialism, Climate Harm and Individual Obligations." Ethical Theory and Moral Practice 18 (1): 177-190.

Nefsky, Julia. 2011. "Consequentialism and the Problem of Collective Harm: A Reply to Kagan.” Philosophy \& Public Affairs 39 (4): 364-395.

Parfit, Derek. 1986. Reasons and Persons. New York, NY: Oxford University Press.

Quast, Troy, Ross Andel, Sean Gregory, and Eric A. Storch. 2020. "Years of Life Lost Associated with COVID-19 Deaths in the United States." Journal of Public Health 42 (4): 717-722.

Schliesser, Eric, and Eric Winsberg. 2020. "Climate and Coronavirus: The Science is Not the Same." New Statesman, March 23, 2020. https://www.newstatesman.com/ politics/economy/2020/03/climate-coronavirus-science-experts-data-sceptics. 
Sinnott-Armstrong, Walter. 2005. "It's Not My Fault: Global Warming and Individual Moral Obligations." In Perspectives on Climate Change: Science, Economics, Politics, Ethics: Volume 5, edited by Walter Sinnott-Armstrong and Richard B. Howarth, 285-307. Bingley: Emerald Group Publishing Limited.

The Directorate of Health. 2021. "COVID-19 in Iceland - Statistics. Statistics from July 12, 2021.” The Directorate of Health and The Department of Civil Protection and Emergency Management. https://www.covid.is/data.

The Economist. 2021. "What is the Economic Cost of Covid-19?" The Economist, January 9, 2021. https://www.economist.com/finance-and-economics/2021/01/09/whatis-the-economic-cost-of-covid-19.

The Guardian. 2020. "WHO Chief Says Herd Immunity Approach to Pandemic 'Unethical'." The Guardian, October 12, 2020. http://www.theguardian.com/world/ 2020/oct/12/who-chief-says-herd-immunity-approach-to-pandemic-unethical.

The World Bank. 2020. "COVID-19 to Add as Many as 150 Million Extreme Poor by 2021.” The World Bank, October 7, 2020. https://www.worldbank.org/en/news/ press-release/2020/10/07/covid-19-to-add-as-many-as-150-million-extreme-poorby-2021.

United Nations. 2020. "Amid Threat of Catastrophic Global Famine, COVID-19 Response Must Prioritize Food Security, Humanitarian Needs, Experts Tell General Assembly." United Nations Meetings Coverage and Press Releases, December 4, 2020. https://www.un.org/press/en/2020/ga12294.doc.htm.

Andrea S. Asker is a PhD candidate at Stockholm University and research assistant at the Institute for Futures Studies in Stockholm. She has an interdisciplinary background with degrees in philosophy and economics from Stockholm University and Lund University. She works on topics in normative and applied ethics and decision theory. Her PhD thesis is on the topic of individual decision making in collective action problems.

Contact e-mail: <andrea.asker@philosophy.su.se>

H. Orri Stefánsson is an associate professor of practical philosophy at Stockholm University and Pro Futura Scientia fellow at the Swedish Collegium for Advanced Study. He holds a $\mathrm{PhD}$ in philosophy from the London School of Economics and Political Science, and has published a number of journal articles, chapters, and a book (together with Katie Steele), mostly on topics in decision theory, normative ethics, and Bayesian epistemology.

Contact e-mail: <orri.stefansson@philosophy.su.se> 